Differ Equ Dyn Syst

DOI 10.1007/s12591-013-0186-2

ORIGINAL RESEARCH

\title{
Fourth Order Impulsive Periodic Boundary Value Problems
}

\author{
J. Fialho • F. Minhós
}

(C) Foundation for Scientific Research and Technological Innovation 2013

Abstract In this work it is presented an existence result for the impulsive problem composed by the fourth order fully nonlinear equation

$$
u^{(i v)}(x)=f\left(x, u(x), u^{\prime}(x), u^{\prime \prime}(x), u^{\prime \prime \prime}(x)\right)
$$

for a.e. $x \in[0,1] \backslash\left\{x_{1}, \ldots, x_{m}\right\}$ where $f:[0,1] \times \mathbb{R}^{4} \rightarrow \mathbb{R}$ is a $L^{1}$-Carathéodory function, along with the periodic boundary conditions

$$
u^{(i)}(0)=u^{(i)}(1), \quad i=0,1,2,3,
$$

and the impulses

$$
\begin{gathered}
u\left(x_{j}^{+}\right)=g_{j}\left(u\left(x_{j}\right)\right), \\
u^{\prime}\left(x_{j}^{+}\right)=h_{j}\left(u^{\prime}\left(x_{j}\right)\right), \\
u^{\prime \prime}\left(x_{j}^{+}\right)=k_{j}\left(u^{\prime \prime}\left(x_{j}\right)\right), \\
u^{\prime \prime \prime}\left(x_{j}^{+}\right)=l_{j}\left(u^{\prime \prime \prime}\left(x_{j}\right)\right),
\end{gathered}
$$
and $g_{j}, h_{j}, k_{j}, l_{j}$ are given real valued functions satisfying some adequate conditions. The arguments used apply lower and upper solutions technique combined with an iterative and non monotone technique.

J. Fialho $(\varangle)$

School of Mathematics, Physics and Technology, College of the Bahamas, Nassau, Bahamas e-mail: jfzero@gmail.com

F. Minhós

Department of Mathematics, School of Sciences and Technology, University of Évora, Évora, Portugal

J. Fialho · F. Minhós

Research Centre on Mathematics and Applications of the University of Évora (CIMA-UE)

Rua Romão Ramalho, 59, 7000-671 Évora, Portugal 


\section{Introduction}

This work will study the nonlinear periodic fourth order impulsive problem composed by the fully differential equation

$$
u^{(i v)}(x)=f\left(x, u(x), u^{\prime}(x), u^{\prime \prime}(x), u^{\prime \prime \prime}(x)\right)
$$

for a.e. $x \in I \backslash\left\{x_{1}, \ldots, x_{m}\right\}$ with $I:=[0,1]$, where $f: I \times \mathbb{R}^{4} \rightarrow \mathbb{R}$ is a $L^{1}$-Carathéodory function. This equation is considered along with the boundary conditions

$$
u^{(i)}(0)=u^{(i)}(1), \quad i=0,1,2,3,
$$

and the impulse conditions

$$
\begin{array}{r}
u\left(x_{j}^{+}\right)=g_{j}\left(u\left(x_{j}\right)\right), \\
u^{\prime}\left(x_{j}^{+}\right)=h_{j}\left(u^{\prime}\left(x_{j}\right)\right), \\
u^{\prime \prime}\left(x_{j}^{+}\right)=k_{j}\left(u^{\prime \prime}\left(x_{j}\right)\right), \\
u^{\prime \prime \prime}\left(x_{j}^{+}\right)=l_{j}\left(u^{\prime \prime \prime}\left(x_{j}\right)\right),
\end{array}
$$

where $x_{j} \in(0,1)$, for $j=1, \ldots, m$, such that $0=x_{0}<x_{1}<\cdots<x_{m}<x_{m+1}=1$ and $g_{j}, h_{j}, k_{j}$ and $l_{j}$ are given real valued functions verifying some adequate conditions to be precise.

The theory of impulsive problems is experiencing a rapid development in the last few years, mainly because impulsive differential equations have been used to describe real phenomena where there are instantaneous changes at some time instants. These changes may occur not only at a micro scale but also at a global level. Applications can be found in a wide range of areas, such as physics, medicine, biology, control theory, population and/or gene dynamics (see $[1,11,18]$ and the references therein).

The monotone iterative technique coupled with lower and upper solutions is a powerful method used to approximate solutions in several nonlinear problems in general and periodic ones in particular (see, for instance, [7,10,12,14-17,19]).

As far as we know, it is the first time that the above methods are applied to fourth-order periodic impulsive problem with a fully differential equation, that is, where the nonlinearity can depend in every derivatives till the third order. Moreover, this paper introduces several other new features:

- The assumptions on the nonlinear part $f$ are more general than the ones usually considered. As example, we mention that no global monotonicity conditions are assumed, neither a Nagumo-type condition to control a subquadratic growth of $f$ on the third derivative.

- An iterative technique, not necessarily monotone, is used to obtain the existence of solutions.

- The impulsive effects, given by (3), are given by general functions, not necessarily linear.

The arguments make use of lower and upper solutions approach to higher order problems suggested in [3-5,9,8], and an iterative method as in [2].

The work is organized in the following way: "Definitions and Auxiliary Results" section contains the definitions used and a uniqueness result for some fourth order problems. The main result, an existence and location theorem, is presented in "Existence of Solutions" section. An example is shown in last section, to illustrate the main theorem. 
51

\section{Definitions and Auxiliary Results}

In this section some notations, definitions and auxiliary results, needed for the main existence result, are presented.

For $m \in \mathbb{N}$, let $0=x_{0}<x_{1}<\cdots<x_{m}<x_{m+1}=1, D=\left\{x_{1}, \ldots, x_{m}\right\}$ and

$$
u\left(x_{k}^{ \pm}\right):=\lim _{x \rightarrow x_{k}^{ \pm}} u(x) \text {. }
$$

Definition 1 Denote by $P C(I)$ the set of functions $u: I \rightarrow \mathbb{R}$ continuous on $I \backslash D$ where $u\left(x_{k}^{+}\right)$and $u\left(x_{k}^{-}\right)$exist with $u\left(x_{k}^{-}\right)=u\left(x_{k}\right)$ for $k=1,2, \ldots, m$.

For $u \in P C(I)$, we define the norm by

$$
\|u\|=\sup _{x \in I}|u(x)| .
$$

Consider $P C^{(l)}(I), l=1,2,3$, as the space of the real-valued functions $u$ such that $u^{(j)} \in P C(I), u^{(j)}\left(x_{k}^{+}\right)$and $u^{(j)}\left(x_{k}^{-}\right)$exist with $u^{(j)}\left(x_{k}^{-}\right)=u^{(j)}\left(x_{k}\right)$ for $j=0,1,2,3$ and $k=1,2, \ldots, m$.

Therefore $u \in P C^{3}(I)$ can be written as

$$
\begin{aligned}
& \qquad u(x)=\left\{\begin{array}{l}
u_{0}(x) \quad \text { if } x \in\left[0, x_{1}\right], \\
u_{1}(x) \quad \text { if } x \in\left(x_{1}, x_{2}\right], \\
\vdots \\
u_{m}(x) \text { if } x \in\left(x_{m}, 1\right],
\end{array}\right. \\
& \text { where } u_{m}=v_{m \mid\left(x_{i}, x_{i+1}\right]} \text { with } v_{m} \in C^{3}\left(\left[x_{i}, x_{i+1}\right]\right) \text { for } i=0,1, \ldots, m . \\
& \text { Denote } \\
& \qquad P C_{D}^{3}(I)=\left\{u \in P C^{3}(I): u^{\prime \prime \prime} \in A C\left(x_{i}, x_{i+1}\right), i=0,1, \ldots, m\right\}
\end{aligned}
$$

Moreover for $p \in L^{1}(I)$ we consider the usual norm

$$
\|p\|_{1}:=\int_{I}|p(t)| \mathrm{d} t .
$$

Throughout this paper the following hypothesis will be assumed:

(H1) $f:[0,1] \times \mathbb{R}^{4} \rightarrow \mathbb{R}$ is a $L^{1}$-Carathéodory function, that is, $f(x, \cdot, \cdot, \cdot, \cdot)$ is a continuous function for a. e. $x \in I$;

$f\left(\cdot, y_{0}, y_{1}, y_{2}, y_{3}\right)$ is measurable for $\left(y_{0}, y_{1}, y_{2}, y_{3}\right) \in \mathbb{R}^{4}$; and for every $M>0$ there is a real-valued function $\psi_{M} \in L^{1}([0,1])$ such that

$$
\left|f\left(x, y_{0}, y_{1}, y_{2}, y_{3}\right)\right| \leq \psi_{M}(x) \text { for a. e. } x \in[0,1]
$$

and for every $\left(y_{0}, y_{1}, y_{2}, y_{3}\right) \in \mathbb{R}^{4}$ with $\left|y_{i}\right| \leq M$ for $i=0,1,2,3$.

(H2) the real valued functions $g_{j}, h_{j}, k_{j}$ and $l_{j}$ are nondecreasing for $j=1, \ldots, m$.

Definition 2 A function $u \in P C_{D}^{3}(I)$ is a solution of (1)-(3) if it satisfies (1) almost everywhere in $I \backslash D$, the periodic conditions (2) and the impulse conditions (3). 
Next lemma will have a key role in the results presented forward.

Lemma 3 Let $p:[0,1] \times \mathbb{R} \rightarrow \mathbb{R}$ be a $L^{1}$-Carathéodory function such that $p(x, v)$ is nonincreasing on $v$, for every $x \in[0,1]$.

Then for each $a_{j}, b_{j}, c_{j}, d_{j} \in \mathbb{R}, j=0,1,2, \ldots, m$, the initial value problem composed by the equation

$$
u^{(i v)}(x)=p\left(x, u^{\prime \prime \prime}(x)\right) \text { for a.e. } x \in(0,1)
$$

and the boundary conditions

$$
u\left(x_{j}^{+}\right)=a_{j}, \quad u^{\prime}\left(x_{j}^{+}\right)=b_{j}, \quad u^{\prime \prime}\left(x_{j}^{+}\right)=c_{j}, \quad u^{\prime \prime \prime}\left(x_{j}^{+}\right)=d_{j}
$$

has a unique solution $u \in P C_{D}^{3}(I)$.

Proof The solution of problem (5)-(6) can be written as

$$
\begin{aligned}
u(x)= & a_{j}+b_{j}\left(x-x_{j}^{+}\right)+c_{j} \frac{\left(x-x_{j}^{+}\right)^{2}}{2} \\
& +d_{j} \frac{\left(x-x_{j}^{+}\right)^{3}}{3 !}+\int_{x_{j}^{+}}^{x} \frac{(x-r)^{3}}{3 !} p\left(r, u^{\prime \prime \prime}(r)\right) \mathrm{d} r .
\end{aligned}
$$

As $p(x)$ is bounded in $I$, we can define $N:=\left\|p\left(x, u^{\prime \prime \prime}(x)\right)\right\|_{1}$ and the following estimates can be obtained:

$$
\begin{aligned}
& |u(x)| \leq\left|a_{j}\right|+\left|b_{j}\right|+\frac{\left|c_{j}\right|}{2}+\frac{\left|d_{j}\right|}{3 !}+N, \\
& \left|u^{\prime}(x)\right| \leq\left|b_{j}\right|+\left|c_{j}\right|+\frac{\left|d_{j}\right|}{2}+N, \\
& \left|u^{\prime \prime}(x)\right| \leq\left|c_{j}\right|+\left|d_{j}\right|+N, \\
& \left|u^{\prime \prime \prime}(x)\right| \leq\left|d_{j}\right|+N .
\end{aligned}
$$

Hence, for $\delta:=\left|a_{j}\right|+2\left|b_{j}\right|+\frac{5}{2}\left|c_{j}\right|+\frac{8}{3}\left|d_{j}\right|+4 N$,

$$
\|u\|_{D} \leq \delta .
$$

Let $u \in P C_{D}^{3}(I)$ such that $\|u\|_{D} \leq \delta$.

Define the operator $\mathcal{T}: P C_{D}^{3}(I) \rightarrow P C_{D}^{3}(I)$ given by

$$
\begin{aligned}
\mathcal{T} u:= & a_{j}+b_{j}\left(x-x_{j}^{+}\right)+c_{j} \frac{\left(x-x_{j}^{+}\right)^{2}}{2} \\
& +d_{j} \frac{\left(x-x_{j}^{+}\right)^{3}}{3 !}+\int_{x_{j}^{+}}^{x} \frac{(x-r)^{3}}{3 !} p\left(r, u^{\prime \prime \prime}(r)\right) \mathrm{d} r .
\end{aligned}
$$

As $p\left(x, u^{\prime \prime \prime}(x)\right)$ is a $L^{1}$-Carathé odory function, then $\mathcal{T}$ is continuous and, by (8),

$$
\left\|\mathcal{T} u_{n}\right\|_{D}=\left\|\mathcal{T} u_{n}\right\|+\left\|\left(\mathcal{T} u_{n}\right)^{\prime}\right\|+\left\|\left(\mathcal{T} u_{n}\right)^{\prime \prime}\right\|+\left\|\left(\mathcal{T} u_{n}\right)^{\prime \prime \prime}\right\| \leq \delta .
$$

Springer 
Given that $\mathcal{T}$ is uniformly bounded and equicontinuous, by Ascoli-Arzela's theorem, $\mathcal{T}$ is a compact operator. Then the set of solutions of the equation $u=\mathcal{T} u$ is bounded. By Schauder fixed point theorem, $\mathcal{T}$ has a fixed point $u \in P C_{D}^{3}(I)$ which satisfies (7) and

$$
u\left(x_{j}^{+}\right)=a_{j}, u^{\prime}\left(x_{j}^{+}\right)=b_{j}, u^{\prime \prime}\left(x_{j}^{+}\right)=c_{j} \quad \text { and } \quad u^{\prime \prime \prime}\left(x_{j}^{+}\right)=d_{j} .
$$

This proves the existence of solution for (5), (6).

To show uniqueness, we will assume that the problem (5), (6) has two solutions, $u_{1}$ and $u_{2}$, define $z(x)=u_{1}^{\prime \prime \prime}(x)-u_{2}^{\prime \prime \prime}(x)$ for $\left.\left.x \in\right] x_{j}, x_{j+1}\right]$.

By (4),

$$
z(x) z^{\prime}(x)=\left[u_{1}^{\prime \prime \prime}(x)-u_{2}^{\prime \prime \prime}(x)\right]\left[p\left(x, u_{1}^{\prime \prime \prime}(x)\right)-p\left(x, u_{2}^{\prime \prime \prime}(x)\right)\right] \leq 0
$$

for $\left.x \in] x_{j}, x_{j+1}\right]$

On the other hand as $z\left(x_{j}^{+}\right)=0$,

$$
\int_{x_{j}^{+}}^{x} z(t) z^{\prime}(t) d t=\frac{(z(x))^{2}}{2}-\frac{\left(z\left(x_{j}^{+}\right)\right)^{2}}{2} \geq 0 .
$$

So $z(x)=0$ for every $\left.x \in] x_{j}, x_{j+1}\right]$. By integration and (6), $u_{1}^{\prime \prime \prime}(x)=u_{2}^{\prime \prime \prime}(x)$ for $x \in$ ]$\left.x_{j}, x_{j+1}\right]$.

Another important tool used in the proof of the main result is the upper and lower solutions technique. Definition is as follows:

Definition 4 A function $\alpha \in P C_{D}^{3}(I)$ is said to be a lower solution of the problem (1)-(3) if:

(i) $\alpha^{(i v)}(x) \leq f\left(x, \alpha(x), \alpha^{\prime}(x), \alpha^{\prime \prime}(x), \alpha^{\prime \prime \prime}(x)\right)$ for a.e. $x \in(0,1)$.

(ii) $\alpha(0) \leq \alpha(1), \alpha^{\prime}(0) \leq \alpha^{\prime}(1), \alpha^{\prime \prime}(0) \leq \alpha^{\prime \prime}(1), \alpha^{\prime \prime \prime}(0) \leq \alpha^{\prime \prime \prime}(1)$,

(iii) $\alpha\left(x_{j}^{+}\right) \leq g_{j}\left(\alpha\left(x_{j}\right)\right), \alpha^{\prime}\left(x_{j}^{+}\right) \leq h_{j}\left(\alpha^{\prime}\left(x_{j}\right)\right), \alpha^{\prime \prime}\left(x_{j}^{+}\right) \leq k_{j}\left(\alpha^{\prime \prime}\left(x_{j}\right)\right), \alpha^{\prime \prime \prime}\left(x_{j}^{+}\right) \leq$ $l_{j}\left(\alpha^{\prime \prime \prime}\left(x_{j}\right)\right)$,

A function $\beta \in P C_{D}^{3}(I)$ is an upper solution of problem (1)-(3) if the reversed inequalities hold.

\section{Existence of Solutions}

In this section the main existence and location result is the following:

Theorem 5 Let $\alpha, \beta \in P C_{D}^{3}(I)$ be, respectively, lower and upper solutions of (1)-(3) such that

$$
\alpha^{\prime \prime \prime}(x) \leq \beta^{\prime \prime \prime}(x) \text { on } I \backslash D
$$

and

$$
\alpha^{(i)}(0) \leq \beta^{(i)}(0), \quad i=0,1,2 .
$$

Assume that

$$
f\left(x, \alpha, \alpha^{\prime}, \alpha^{\prime \prime}, y_{3}\right) \leq f\left(x, y_{0}, y_{1}, y_{2}, y_{3}\right) \leq f\left(x, \beta, \beta^{\prime}, \beta^{\prime \prime}, y_{3}\right)
$$


for fixed $\left(x, y_{3}\right) \in I \times \mathbb{R}, \alpha^{(i)} \leq y_{i} \leq \beta^{(i)}$ for $i=0,1,2$ and $f\left(x, y_{0}, y_{1}, y_{2}, y_{3}\right)$ is nonincreasing on $y_{3}$ for $x \in[0,1]$.

If conditions (H1) and (H2) hold, then the problem (1)-(3) has a solution $u(x) \in P C_{D}^{3}(I)$, such that

$$
\alpha^{(i)}(x) \leq u^{(i)}(x) \leq \beta^{(i)}(x) \text {, on } I, \text { for } i=0,1,2,3 .
$$

Remark 6 As one can notice by (11), the inequalities $\alpha^{(i)}(x) \leq \beta^{(i)}(x)$ hold for $i=0,1,2$ and every $x \in I$.

Proof Consider the following modified problem composed by the equation

$$
\begin{aligned}
u^{(i v)}(x)= & f\left(x, \delta_{0}(x, u(x)), \delta_{1}\left(x, u^{\prime}(x)\right), \delta_{2}\left(x, u^{\prime \prime}(x)\right), \delta_{3}\left(x, u^{\prime \prime \prime}(x)\right)\right) \\
& -u^{\prime \prime \prime}(x)+\delta_{3}\left(x, u^{\prime \prime \prime}(x)\right)
\end{aligned}
$$

for $x \in(0,1)$ and $x \neq x_{j}$ where the continuous functions $\delta_{i}: \mathbb{R}^{2} \rightarrow \mathbb{R}$, for $i=0,1,2,3$, are given by

$$
\delta_{i}\left(x, y_{i}\right)= \begin{cases}\beta^{(i)}(x), & y_{i}>\beta^{(i)}(x), \\ y_{i}, & \alpha^{(i)}(x) \leq y_{i} \leq \beta^{(i)}(x), \\ \alpha^{(i)}(x), & y_{i}<\alpha^{(i)}(x),\end{cases}
$$

with the boundary conditions (2) and the impulse conditions (3).

To prove the existence of solution for the problem (13), (2), (3) we apply an iterative technique, not necessarily monotone. Let $\left(u_{n}\right)_{n \in \mathbb{N}}$ be the sequence in $P C_{D}^{3}(I)$ defined as follows:

$$
u_{0}(x)=\alpha(x),
$$

and for $n=1,2, \ldots$ the problem composed by Eq. (11)

$$
\begin{aligned}
u_{n}^{(i v)}(x)= & f\left(x, \delta_{0}\left(x, u_{n-1}(x)\right), \delta_{1}\left(x, u_{n-1}^{\prime}(x)\right), \delta_{2}\left(x, u_{n-1}^{\prime \prime}(x)\right), \delta_{3}\left(x, u_{n}^{\prime \prime \prime}(x)\right)\right) \\
& +u_{n}^{\prime \prime \prime}(x)-\delta_{3}\left(x, u_{n}^{\prime \prime \prime}(x)\right) \text { for a.e. } x \in(0,1)
\end{aligned}
$$

with the boundary conditions

$$
\begin{array}{ll}
u_{n}(0)=u_{n-1}(1), & u_{n}^{\prime}(0)=u_{n-1}^{\prime}(1), \\
u_{n}^{\prime \prime}(0)=u_{n-1}^{\prime \prime}(1), & u_{n}^{\prime \prime \prime}(0)=u_{n-1}^{\prime \prime \prime}(1),
\end{array}
$$

and the impulsive conditions, for $j=1, \ldots, m$,

$$
\begin{gathered}
u_{n}\left(x_{j}^{+}\right)=g_{j}\left(u_{n-1}\left(x_{j}\right)\right), \quad u_{n}^{\prime}\left(x_{j}^{+}\right)=h_{j}\left(u_{n-1}^{\prime}\left(x_{j}\right)\right), \\
u_{n}^{\prime \prime}\left(x_{j}^{+}\right)=k_{j}\left(u_{n-1}^{\prime \prime}\left(x_{j}\right)\right), \quad u_{n}^{\prime \prime \prime}\left(x_{j}^{+}\right)=l_{j}\left(u_{n-1}^{\prime \prime \prime}\left(x_{j}\right)\right) .
\end{gathered}
$$

Problem (5)-(6) is an initial value problem, however considering in (13) fixed $\left(y_{0}, y_{1}, y_{2}\right)$ the function $f\left(y_{0}, y_{1}, y_{2}, y_{3}\right)$ verifies (5) and, therefore, the sequence $\left(u_{n}\right)_{n \in \mathbb{N}}$ is well defined by the uniqueness given by Lemma 3 .

Remark that the initial value problem (16)-(18) will become the periodic impulsive problem (1)-(3), if the two following claims hold:

- Every solution $u_{n}(x)$ of the problem (16)-(18) verifies

$$
\alpha^{(i)}(x) \leq u_{n}^{(i)}(x) \leq \beta^{(i)}(x) \text { for } i=0,1,2,3,
$$


for all $n \in \mathbb{N}$ and every $x \in I$, which implies that

$$
\delta_{i}\left(x, u_{n}^{(i)}(x)\right)=u_{n}^{(i)}(x) \text { for } i=0,1,2,3, n \in \mathbb{N} \text { and every } x \in I .
$$

- The sequence $\left(u_{n}\right)_{n \in \mathbb{N}}$ is convergent to a solution $u \in P C_{D}^{3}$ of problem (16)-(18).

Step 1 - Every solution of problem (16)-(18) verifies

$$
\alpha^{(i)}(x) \leq u_{n}^{(i)}(x) \leq \beta^{(i)}(x) \text { for } i=0,1,2,3,
$$

for all $n \in \mathbb{N}$ and every $x \in I$.

Let $u$ be a solution of the problem (16)-(18). To prove inequalities (19) we will rely on mathematical induction.

For $n=0$, by (15),

$$
\alpha^{\prime \prime \prime}(x)=u_{0}^{\prime \prime \prime}(x) \leq \beta^{\prime \prime \prime}(x) \text { for } x \in I
$$

and by, Remark 6,

$$
\alpha^{(i)}(x) \leq u_{0}^{(i)}(x) \leq \beta^{(i)}(x) \text { for } i=0,1,2 \text {, and } x \in I .
$$

Suppose that for $k=1, \ldots, n-1$ and every $x \in I$ we have

$$
\alpha^{\prime \prime \prime}(x) \leq u_{k}^{\prime \prime \prime}(x) \leq \beta^{\prime \prime \prime}(x)
$$

for $x=0$, by (17), (21) and Definition 4, we have

$$
u_{n}^{\prime \prime \prime}(0)=u_{n-1}^{\prime \prime \prime}(1) \geq \alpha^{\prime \prime \prime}(1) \geq \alpha^{\prime \prime \prime}(0) .
$$

If $x=x_{j}^{+}, j=1, \ldots, m$, from (18), (H2), (21) and Definition 4, then

$$
u_{n}^{\prime \prime \prime}\left(x_{j}^{+}\right)=l_{j}\left(u_{n-1}^{\prime \prime \prime}\left(x_{j}\right)\right) \geq l_{j}\left(\alpha^{\prime \prime \prime}\left(x_{j}\right)\right) \geq \alpha^{\prime \prime \prime}\left(x_{j}^{+}\right) .
$$

For $\left.x \in] x_{j}, x_{j+1}\right], j=1,2, \ldots, m$ suppose, by contradiction, that there exists $x^{*} \in$ ]$\left.x_{j}, x_{j+1}\right]$ such that $\alpha^{\prime \prime \prime}\left(x^{*}\right)>u_{n}^{\prime \prime \prime}\left(x^{*}\right)$ and define

$$
\min _{\left.x \in] x_{j}, x_{j+1}\right]} u_{n}^{\prime \prime \prime}(x)-\alpha^{\prime \prime \prime}(x):=u_{n}^{\prime \prime \prime}\left(x^{*}\right)-\alpha^{\prime \prime \prime}\left(x^{*}\right)<0 .
$$

As by (18), $u_{n}^{\prime \prime \prime}\left(x_{j}^{+}\right) \geq \alpha^{\prime \prime \prime}\left(x_{j}^{+}\right)$, then there is an interval $(\underline{x}, \bar{x}) \subset\left(x_{j}, x^{*}\right)$ such that

$$
u_{n}^{\prime \prime \prime}(x)<\alpha^{\prime \prime \prime}(x) \text { and } u_{n}^{(i v)}(x) \leq \alpha^{(i v)}(x) \forall x \in(\underline{x}, \bar{x}) .
$$

From (16) and (12) the following contradiction is obtained for $x \in(\underline{x}, \bar{x})$ :

$$
\begin{aligned}
0 \geq & u_{n}^{(i v)}(x)-\alpha^{(i v)}(x) \\
= & f\left(x, \delta_{0}\left(x, u_{n-1}(x)\right), \delta_{1}\left(x, u_{n-1}^{\prime}(x)\right), \delta_{2}\left(x, u_{n-1}^{\prime \prime}(x)\right), \alpha^{\prime \prime \prime}(x)\right) \\
& -u^{\prime \prime \prime}(x)+\alpha^{\prime \prime \prime}(x)-\alpha^{(i v)}(x) \\
\geq & f\left(x, \alpha(x), \alpha^{\prime}(x), \alpha^{\prime \prime}(x), \alpha^{\prime \prime \prime}(x)\right)-u^{\prime \prime \prime}(x)+\alpha^{\prime \prime \prime}(x) \\
& -f\left(x, \alpha(x), \alpha^{\prime}(x), \alpha^{\prime \prime}(x), \alpha^{\prime \prime \prime}(x)\right) \\
\geq & \alpha^{\prime \prime \prime}(x)-u^{\prime \prime \prime}(x)>0
\end{aligned}
$$

As $x^{*}$ is taken arbitrarily in $\left.] x_{j}, x_{j+1}\right]$, then $u_{n}^{\prime \prime \prime}(x) \geq \alpha^{\prime \prime \prime}(x)$ for all $n \in \mathbb{N}$ and every $x \in I$. In the same way it can be shown that $u_{n}^{\prime \prime \prime}(x) \leq \beta^{\prime \prime \prime}(x) \forall x \in I, \forall n \in \mathbb{N}$, and so (19) is proved for $i=3$. 
Assuming that for $k=1, \ldots, n-1$ and every $x \in I$,

$$
\alpha^{\prime \prime}(x) \leq u_{k}^{\prime \prime}(x) \leq \beta^{\prime \prime}(x),
$$

then for $x \in\left[0, x_{1}\right]$, by integration of the inequality $u_{n}^{\prime \prime \prime}(x) \geq \alpha^{\prime \prime \prime}(x)$ in $[0, x]$ we have

$$
u_{n}^{\prime \prime}(x)-u_{n}^{\prime \prime}(0) \geq \alpha^{\prime \prime}(x)-\alpha^{\prime \prime}(0) .
$$

By (17) and (22),

$$
\begin{aligned}
u_{n}^{\prime \prime}(x) & \geq \alpha^{\prime \prime}(x)-\alpha^{\prime \prime}(0)+u_{n-1}^{\prime \prime}(1) \\
& \geq \alpha^{\prime \prime}(x)-\alpha^{\prime \prime}(0)+\alpha^{\prime \prime}(1) \geq \alpha^{\prime \prime}(x)
\end{aligned}
$$

hence $u_{n}^{\prime \prime}(x) \geq \alpha^{\prime \prime}(x)$, for all $x \in\left[0, x_{1}\right]$.

For $\left.x \in] x_{j}, x_{j+1}\right], j=1,2, \ldots, m$, by integration of the inequality $u_{n}^{\prime \prime \prime}(x) \geq \alpha^{\prime \prime \prime}(x)$ in $\left.x \in] x_{j}, x_{j+1}\right]$

$$
u_{n}^{\prime \prime}(x) \geq \alpha^{\prime \prime}(x)-\alpha^{\prime \prime}\left(x_{j}^{+}\right)+u_{n}^{\prime \prime}\left(x_{j}^{+}\right),
$$

and by (18) and Definition 4

$$
u_{n}^{\prime \prime}(x) \geq \alpha^{\prime \prime}(x)-\alpha^{\prime \prime}\left(x_{j}^{+}\right)+k_{j}\left(u_{n-1}^{\prime \prime}\left(x_{j}\right)\right) \geq \alpha^{\prime \prime}(x),
$$

obtaining that $u_{n}^{\prime \prime}(x) \geq \alpha^{\prime \prime}(x)$ for all $n \in \mathbb{N}$ and every $x \in I$. Using similar arguments it can be proved that $u_{n}^{\prime \prime}(x) \leq \beta^{\prime \prime}(x)$ and therefore

$$
\alpha^{\prime \prime}(x) \leq u_{n}^{\prime \prime}(x) \leq \beta^{\prime \prime}(x) \quad \forall x \in I \quad \forall n \in \mathbb{N} .
$$

The remaining inequalities in (19) can be proved as above, by integration of (22) in $\left[0, x_{1}\right]$ applying the correspondent hypothesis of induction, conditions (17), (18), and Definition 4.

Step 2 - The sequence $\left(u_{n}\right)_{n \in \mathbb{N}}$ is convergent to $u$ solution of problem (16)-(18).

$\overline{\text { For } i}=0,1,2,3$, let $C_{i}=\max \left\{\left\|\alpha^{(i)}\right\|,\left\|\beta^{(i)}\right\|\right\}$. So there exists $M>0$, with $M:=$ $\sum_{i=0}^{3} C_{i}$ and for all $n \in \mathbb{N}$

$$
\left\|u_{n}\right\|_{D} \leq M .
$$

Let $\Omega$ be a compact subset of $\mathbb{R}^{4}$ given by

$$
\Omega=\left\{\left(w_{0}, w_{1}, w_{2}, w_{3}\right) \in \mathbb{R}^{4}:\left\|w_{i}\right\| \leq C_{i}, i=0,1,2,3\right\} .
$$

As $f$ is a $L^{1}$-Carathéodory function in $\Omega$, then there exists a real-valued function $h_{M}(x) \in$ $L^{1}(I)$ such that

$$
\left|f\left(x, w_{0}, w_{1}, w_{2}, w_{3}\right)\right| \leq h_{M}(x) \text { for every }\left(w_{0}, w_{1}, w_{2}, w_{3}\right) \in \Omega .
$$

By Step 1 and (24), $\left(u_{n}, u_{n}^{\prime}, u_{n}^{\prime \prime}, u_{n}^{\prime \prime \prime}\right) \in \Omega$ for all $n \in \mathbb{N}$. From (16) and (25) we obtain

$$
\left|u_{n}^{(i v)}(x)\right| \leq h_{M}(x)+2 C_{3} \quad \text { for a.e. } x \in I,
$$

hence $u_{n}^{(i v)}(x) \in L^{1}(I)$.

By integration in $I$ we obtain that

$$
u_{n}^{\prime \prime \prime}(x)=u_{n}^{\prime \prime \prime}(0)+\int_{0}^{x} u_{n}^{(i v)}(s) \mathrm{d} s+\sum_{0<x_{j} \leq x} l_{j}\left(u_{n-1}^{\prime \prime \prime}\left(x_{j}\right)\right),
$$

Springer

Journal: 12591-DEDS Article No.: $0186 \square$ TYPESET $\square$ DISK $\square$ LE $\square$ CP Disp.:2013/10/18 Pages: 11 Layout: Small 
therefore $u_{n}^{\prime \prime \prime} \in A C\left(x_{j}, x_{j+1}\right)$ and $u_{n} \in P C_{D}^{3}(I)$. By Ascoli-Arzela's theorem there exists a subsequence, denoted by $\left(u_{n}\right)_{n \in \mathbb{N}}$, which converges to $u \in P C_{D}^{3}(I)$. Then $\left(u, u^{\prime}, u^{\prime \prime}, u^{\prime \prime \prime}\right) \in \Omega$.

Using the Lebesgue dominated convergence theorem, for $x \in\left(x_{j}, x_{j+1}\right)$,

$$
\int_{x_{j}}^{x}\left[\begin{array}{l}
f\left(s, \delta_{0}\left(s, u_{n-1}(s)\right), \delta_{1}\left(s, u_{n-1}^{\prime}(s)\right), \delta_{2}\left(s, u_{n-1}^{\prime \prime}(s)\right), \delta_{3}\left(s, u_{n}^{\prime \prime \prime}(s)\right)\right) \\
-u_{n}^{\prime \prime \prime}(s)+\delta_{3}\left(s, u_{n}^{\prime \prime \prime}(s)\right)
\end{array}\right] \mathrm{d} s
$$

is convergent to

$$
\int_{x_{j}}^{x}\left[\begin{array}{l}
f\left(s, \delta_{0}(s, u(s)), \delta_{1}\left(s, u^{\prime}(s)\right), \delta_{2}\left(s, u^{\prime \prime}(s)\right), \delta_{3}\left(s, u^{\prime \prime \prime}(s)\right)\right) \\
-u^{\prime \prime \prime}(s)+\delta_{3}\left(s, u^{\prime \prime \prime}(s)\right)
\end{array}\right] \mathrm{d} s
$$

as $n \rightarrow \infty$.

Therefore as $n \rightarrow \infty$

$u_{n}^{\prime \prime \prime}(x)$

$=u_{n}^{\prime \prime \prime}\left(x_{j}\right)+\int_{x_{j}}^{x}\left[\begin{array}{l}f\left(s, \delta_{0}\left(s, u_{n-1}(s)\right), \delta_{1}\left(s, u_{n-1}^{\prime}(s)\right), \delta_{2}\left(s, u_{n-1}^{\prime \prime}(s)\right), \delta_{3}\left(s, u_{n}^{\prime \prime \prime}(s)\right)\right) \\ -u_{n}^{\prime \prime \prime}(s)+\delta_{3}\left(s, u_{n}^{\prime \prime \prime}(s)\right)\end{array}\right] \mathrm{d} s$.

is convergent to

$u^{\prime \prime \prime}(x)=u^{\prime \prime \prime}\left(x_{j}\right)+\int_{x_{j}}^{x}\left[\begin{array}{l}f\left(s, \delta_{0}(s, u(s)), \delta_{1}\left(s, u^{\prime}(s)\right), \delta_{2}\left(s, u^{\prime \prime}(s)\right), \delta_{3}\left(s, u^{\prime \prime \prime}(s)\right)\right) \\ -u^{\prime \prime \prime}(s)+\delta_{3}\left(s, u^{\prime \prime \prime}(s)\right)\end{array}\right] \mathrm{d} s$.

As the function $f$ is $L^{1}$-Carathéodory function in $\left(x_{j}, x_{j+1}\right)$, then $u^{\prime \prime \prime}(x) \in A C\left(x_{j}, x_{j+1}\right)$. Therefore $u \in P C_{D}^{3}(I)$ and $u$ is a solution of problem (16)-(18).

To prove that $u$ is a solution of the boundary value problem (1)-(3) we note that taking the limit in (17) and (18), as $n \rightarrow \infty$, by the convergence of $u_{n}$ then $u$ verifies (2) and, by the continuity of of the impulsive functions, $u$ verifies (3). By (14), Step 1 and the convergence of $u_{n}, u$ verifies (1).

Then problem (1)-(3) has a solution $u(x) \in P C_{D}^{3}(I)$, such that

$$
\alpha^{(i)}(x) \leq u^{(i)}(x) \leq \beta^{(i)}(x) \text { for } i=0,1,2,3
$$

for $x \in I$.

\section{Example}

Let us consider the following nonlinear periodic impulsive boundary value problem, composed by the equation:

$$
u^{(i v)}(x)=(u(x))^{3}+\arctan \left(u^{\prime}(x)+1\right)+0.01\left(u^{\prime \prime}(x)\right)^{5}+\eta\left|u^{\prime \prime \prime}(x)\right|^{\theta},
$$


where $0 \leq \theta \leq 2$ and $\eta \leq-677$ for all $x \in[0,1] \backslash\left\{\frac{1}{2}\right\}$ along with the boundary conditions (2) and for $x_{j}=\frac{1}{2}$ the impulse conditions

$$
\begin{aligned}
u\left(\frac{1}{2}^{+}\right) & =\mu_{1}\left(u\left(\frac{1}{2}\right)\right)^{3}, \\
u^{\prime}\left(\frac{1}{2}^{+}\right) & =\mu_{2}\left(u^{\prime}\left(\frac{1}{2}\right)\right), \\
u^{\prime \prime}\left(\frac{1}{2}^{+}\right) & =\mu_{3} \sqrt[3]{\left(u^{\prime \prime}\left(\frac{1}{2}\right)\right),} \\
u^{\prime \prime \prime}\left(\frac{1}{2}^{+}\right) & =\mu_{4}\left(u^{\prime \prime \prime}\left(\frac{1}{2}\right)\right)^{5},
\end{aligned}
$$

with $\mu_{i} \in \mathbb{R}^{+}, i=1,2,3,4$.

Obviously this problem is a particular case of (1)-(3) with

$$
f\left(x, y_{0}, y_{1}, y_{2}, y_{3}\right)=\left(y_{0}\right)^{3}+\arctan \left(y_{1}+1\right)+0.01\left(y_{2}\right)^{5}+\eta\left|y_{3}\right|^{\theta},
$$

for all $x \in[0,1] \backslash\left\{\frac{1}{2}\right\}, m=1, x_{1}=\frac{1}{2}$ and the nondecreasing functions $g_{1}, h_{1}, k_{1}$ and $l_{1}$ are given by

$$
g_{1}(x)=\mu_{1} x^{3}, \quad h_{1}(x)=\mu_{2} x, \quad k_{1}(x)=\mu_{3} \sqrt[3]{x}, \quad l_{1}(x)=\mu_{4} x^{5} .
$$

The functions $\alpha(x)=0$ and

$$
\beta(x)= \begin{cases}x^{3}+3 x^{2}+4 x+\frac{3}{2}, & x \in\left[0, \frac{1}{2}\right], \\ x^{3}, & x \in\left(\frac{1}{2}, 1\right]\end{cases}
$$

are $P C_{D}^{3}(I)$ for $D=\left\{\frac{1}{2}\right\}$ with

$$
\beta^{\prime}(x)= \begin{cases}3 x^{2}+6 x+4, & x \in\left[0, \frac{1}{2}\right], \\ 3 x^{2}, & x \in\left(\frac{1}{2}, 1\right],\end{cases}
$$

$$
\beta^{\prime \prime}(x)= \begin{cases}6 x+6, & x \in\left[0, \frac{1}{2}\right], \\ 6 x, & x \in\left(\frac{1}{2}, 1\right],\end{cases}
$$

$$
\beta^{\prime \prime \prime}(x)=6, \quad x \in[0,1]
$$

are lower and upper solutions, respectively, for problem (26), (2), (27), with

$$
\mu_{1} \leq \frac{64}{42875}, \quad \mu_{2} \leq \frac{3}{31}, \quad \mu_{3} \leq \sqrt[3]{3}, \quad \mu_{4} \leq \frac{1}{6^{4}} .
$$

As $f$ verifies (12), by Theorem 5 there is a non-negative solution $u(x) \in P C_{D}^{3}(I)$, such that

$$
0 \leq u^{(i)}(x) \leq \beta^{(i)}(x) \text { for } i=0,1,2,3 .
$$

Remark that this solution cannot be a trivial periodic one, as the only constant verifying (26) is $-\sqrt[3]{\pi / 4}$ and it does not satisfy (28). 


\section{References}

1. Bellman, R.: Mathematical Methods in Medicine. World Scientific, Singapore (1983)

2. Benbouziane, Z., Boucherif, A., Bouguima, S.: Existence result for impulsive third order periodic boundary value problems. Appl. Math. Comput. 206, 728-737 (2008)

3. Cabada, A., Minhós, F.: Fully nonlinear fourth-order equations with functional boundary conditions. J. Math. Anal. Appl. 340, 239-251 (2008)

4. Cabada, A., Minhós, F., Santos, A.: Solvability for a third order discontinuous fully equation with nonlinear functional boundary conditions. J. Math. Anal. Appl. 322, 735-748 (2006)

5. Cabada, A., Pouso, R., Minhós, F.: Extremal solutions to fourth-order functional boundary value problems including multipoint conditions. Nonlinear Anal. Real World Appl. 10, 2157-2170 (2009)

6. Cabada, A., Tomeček, J.: Extremal solutions for nonlinear functional $\phi$-Laplacian impulsive equations. Nonlinear Anal. 67, 827-841 (2007)

7. Ding, W., Mi, J., Han, M.: Periodic boundary value problems for the first order impulsive functional differential equations. Appl. Math. Comput. 165, 433-446 (2005)

8. Fialho, J., Minhós, F.: Existence and location results for hinged beam equations with unbounded nonlinearities. Nonlinear Anal. 71, e1519-e1526 (2009)

9. Graef, J., Kong, L., Minhós, F., Fialho, J.: On lower and upper solutions method for higher order functional boundary value problems. Appl. Anal. Discret. Math. 5, 133-146 (2011)

10. He, Z., Yu, J.: Periodic boundary value problem for first-order impulsive ordinary differential equations. J. Math. Anal. Appl. 272, 67-78 (2002)

11. Lakshmikantham, V., Baĭnov, D., Simeonov, P.: Theory of Impulsive Differential Equations. Series in Modern Applied Mathematics, vol. 6. World Scientific Publishing Co. Inc., Singapore (1989)

12. Liang, R., Shen, J.: Periodic boundary value problem for the first order impulsive functional differential equations. J. Comput. Appl. Math. 202, 498-510 (2007)

13. Liu, Y., Ge, W.: Solutions of a generalized multi-point conjugate BVPs for higher order impulsive differential equations. Dyn. Syst. Appl. 14, 265-279 (2005)

14. Luo, Z., Jing, Z.: Periodic boundary value problem for first-order impulsive functional differential equations. Comput. Math. Appl. 55, 2094-2107 (2008)

15. Liz, E., Nieto, J.: Periodic solutions of discontinuous impulsive differential systems. J. Math. Anal. Appl. 161, 388-394 (1991)

16. Nieto, J., Rodriguez-López, R.: Existence and approximation of solutions for nonlinear functional differential equations with periodic boundary value conditions. Comput. Appl. Math. 40, 433-442 (2000)

17. Rachunková, I., Tvrdý, M.: Existence results for impulsive second-order periodic problems. Nonlinear Anal. 59, 133-146 (2004)

18. Samoilenko, A.M., Perestyuk, N.A.: Impulsive Differential Equations. World Scientific, Singapore (1995)

19. Wang, X., Zhang, J.: Impulsive anti-periodic boundary value problem of first-order integro-differential equations. J. Comput. Appl. Math. 234, 3261-3267 (2010) 